\title{
A Greenhouse Method for Screening Grapevine Seedlings for Resistance to Anthracnose
}

\author{
D.L. Hopkins ${ }^{1}$ and J.W. Harris ${ }^{2}$ \\ Central Florida Research and Education Center, University of Florida, 5336 \\ University Avenue, Leesburg, FL 34748
}

Additional index words. Vitis sp., Elsinoe ampelina, fungus, disease

\begin{abstract}
Screening for resistance to Elsinoe ampelina (de Bary) Shear, causal agent of grape anthracnose, in grapevine seedlings is commonly conducted by natural infection over 3 to 4 years in the vineyard. The objective of this research was to develop a greenhouse screening method for selecting grapevine seedlings with resistance to anthracnose. Spores of $E$. ampelina were obtained from 3- to 4-week-old cultures on potato dextrose agar. Inoculum concentrations ranging from $1.3 \times 10^{3}$ to $1.3 \times 10^{7} E$. ampelina conidia per $\mathrm{mL}$ were evaluated and $10^{6}$ conidia/mL was optimum. The time of incubation of seedlings in a moist chamber after inoculation varied from 24 to 120 hours with 24 to 72 hours resulting in good symptom development. Temperatures in the moist chamber from 16 to $32{ }^{\circ} \mathrm{C}$ were evaluated and the most consistent results were obtained at 20 to $28{ }^{\circ} \mathrm{C}$. The most effective method for selecting anthracnose-resistant grape seedlings in the two-to-three true-leaf stage was misting the seedlings with a suspension containing $10^{6} \mathrm{conidia} / \mathrm{mL}$ in water and placing the inoculated seedlings in a moist chamber at $24^{\circ} \mathrm{C}$ for 48 hours, followed by 8 days on a greenhouse bench. Resistant seedlings from the greenhouse screening (those with $<10$ foliar lesions) were transplanted into the vineyard and found to be resistant to anthracnose infection under rainy, humid conditions. This greenhouse procedure for selecting grapevine cultivars and breeding lines with resistance to anthracnose is accurate, economical, and labor-saving.
\end{abstract}

Anthracnose is especially damaging to grapevines grown in rainy, humid regions (Mirica, 1988). Lesions may occur on leaves, shoots, petioles, rachises, pedicels, and berries and are generally circular with brown to black margins and with round or angular edges. Young, green, succulent tissue is most susceptible and growing points of shoots are often killed. Frequent fungicide applications are required to control anthracnose in Florida. In years with excessive rainfall, control of anthracnose in susceptible cultivars is practically impossible even with fungicide applications every 7 to $10 \mathrm{~d}$ (Hopkins, 1973). Yield losses due to anthracnose and the expense of numerous fungicide applications make the profitable production of susceptible grape cultivars difficult in areas with warm, humid climates.

Conidia of E. ampelina can germinate and infect at 2 to $32{ }^{\circ} \mathrm{C}$ (Mirica, 1988). In culture, the fungus grows best at $28{ }^{\circ} \mathrm{C}$, but will not grow at $35^{\circ} \mathrm{C}$ (Tanaka et al., 1974). Wetness periods necessary for infection were found to be 7 to $10 \mathrm{~h}$ at $12{ }^{\circ} \mathrm{C}$ and 3 to $4 \mathrm{~h}$ at $21^{\circ} \mathrm{C}$

\footnotetext{
Received for publication 14 Sept. 1998. Accepted for publication 24 Feb. 1999. Univ. of Florida Agricultural Experiment Station Journal Series Paper No. R-05844. The cost of publishing this paper was defrayed in part by the payment of page charges. Under postal regulations, this paper therefore must be hereby marked advertisement solely to indicate this fact.

${ }^{1}$ Professor.

${ }^{2}$ Senior Lab Technician.
}

(Brook, 1973). The optimal temperatures for disease development are 24 to $26^{\circ} \mathrm{C}$ (Mirica, 1988).

Cultivars resistant to anthracnose can be obtained by transferring resistance from species of Vitis native to the eastern United States (Fennell, 1948; Rogers and Mortensen, 1979). Mortensen (1981) proposed a trigenic hypothesis for resistance to anthracnose in grapevine that explained the ratios of resistant to susceptible seedlings observed in segregating populations. Two dominant genes for susceptibility $\left(\mathrm{An}_{1}\right.$ and $\left.\mathrm{An}_{2}\right)$ and a single dominant gene conditioning resistance $\left(\mathrm{An}_{3}\right)$ were described, with independent inheritance of the three genes.

At the Univ. of Florida, screening of grapevine seedlings for resistance to anthracnose currently is done in the vineyard by rating for natural infection during the warm, humid summer months for 3 to 4 years. This is costly and inefficient in terms of labor and land use. The purpose of this research was to develop a method for selecting the resistant progeny in the young seedling stage, so that the susceptible seedlings could be discarded prior to planting the progeny in the field.

\section{Materials and Methods}

Plant material. Plant material used in this work consisted of seedlings from self-pollinated, Univ. of Florida-developed hybrid bunch grapes 'Blue Lake', 'Lake Emerald', and 'Stover' (Vitis sp.) (Halbrooks and Mortensen, 1989) and seedlings from a cross between 'Stover' and 'Blue Lake'. Field evalu- ations and genetic analysis have shown that progeny of 'Blue Lake' segregate into a 3:1 ratio of resistant to susceptible plants; 'Lake Emerald' and 'Stover' segregate into a 21:43 ratio (Mortensen, 1981). Genetic analysis showed that a 'Blue Lake' $\mathrm{x}$ 'Stover' cross should result in a 1:1 ratio of resistant to susceptible plants in the progeny (Mortensen, 1981).

Pathogen. Two isolates of E. ampelina were obtained by culturing from naturally infected grapevine stems from the Central Florida Research and Education Center vineyard in Leesburg. These two cultures were maintained on potato dextrose agar and used throughout the study. The isolates were used separately and results of the various experiments were very similar with both isolates. Conidial suspensions were obtained from a 3to 4-week-old culture by flooding the culture plate with sterile, distilled water and scraping the surface of the culture with a scalpel. The suspension was then filtered through four layers of cheesecloth to remove aggregates of mycelium. A hemacytometer was used to determine the concentration of the conidial suspensions.

Greenhouse methods. After stratification, grape seed were planted in a commercial soil mix (Metro-Mix 500 Growing Medium; ScottsSierra, Marysville, Ohio) in 40-cm-wide $\times 60$ $\mathrm{cm}$-long $\times 6$-cm-deep wooden flats. Seeds were planted in eight $40-\mathrm{cm}$ rows with 20 seeds per row. Germination varied from $80 \%$ to $90 \%$. Grape seedlings in the two-to-three true-leaf stage were inoculated by misting with a suspension of conidia and covered with a plastic chamber, consisting of 4-mil (0.1$\mathrm{mm})$, clear, plastic greenhouse covering (Armin Plastics, City of Industry, Calif.) on a wooden frame $125 \times 130 \times 26 \mathrm{~cm}$. Six flats of seedlings fit under each chamber. The table under the cover was lined with water-soaked paper towels to maintain a relative humidity of $95 \%$ to $100 \%$. A hygrothermograph was placed in the chamber to record temperature and humidity.

Anthracnose ratings. After removal of the moist chamber, the seedlings were kept on the greenhouse bench and foliar lesions were counted $10 \mathrm{~d}$ after inoculation. Preliminary experiments with seedlings of known susceptibility to anthracnose indicated that resistant seedlings would have $<10$ lesions per seedling in most cases and susceptible seedlings generally had >20 lesions; therefore, seedlings with $<10$ foliar lesions were considered to be resistant.

Experimental design and statistical analysis. For all greenhouse experiments, a randomized block design was used, with four replications per treatment and 40 seeds per replication. Data were analyzed after arcsine square root transformation. Data were subjected to analysis of variance using the general linear models (GLM) procedure of SAS (SAS Institute, Cary, N.C.).

Inoculum concentration. To determine optimum conidial concentration, seedlings of 'Blue Lake' and 'Lake Emerald' were inoculated with 10 -fold dilutions of conidial sus- 
pensions ranging from $1.3 \times 10^{3}$ to $1.3 \times 10^{7}$ conidia $/ \mathrm{mL}$. The seedlings remained in the moist chamber for $72 \mathrm{~h}$ and temperature under the chamber ranged from 18 to $30{ }^{\circ} \mathrm{C}$. This experiment was repeated two more times with conidial concentrations of $10^{5}, 5 \times 10^{5}, 10^{6}, 5$ $\times 10^{6}$, and $10^{7}$ conidia $/ \mathrm{mL}$.

Incubation temperature. The effects of variations in median temperature were evaluated. Tests were conducted at 16, 20, 24, 28, and $32{ }^{\circ} \mathrm{C}$ with moist chamber incubation times of 24,48 , and $72 \mathrm{~h}$ at each temperature. The inoculum concentration was $1 \times 10^{6}$ conidia $/ \mathrm{mL}$. These experiments were repeated at least twice for each temperature during December to April in the winters of 1991-92 and 1992-93.

Duration of moist chamber incubation. To determine the optimum time in the moist chamber, inoculated seedlings were enclosed for times ranging from 24 to $120 \mathrm{~h}$ by 24 -h increments with a standard temperature of $24{ }^{\circ} \mathrm{C}$. The inoculum concentration was $1 \times 10^{6}$ conidia/ $\mathrm{mL}$. This experiment was repeated four times.

Validation of greenhouse method. Using a greenhouse screening procedure based on the results of the experiments described above, seedlings from selfed cultivars and crosses were tested for resistance and the results were compared with the known segregation ratios obtained from prior genetic analysis (Mortensen, 1981). The data were subjected to chi-square analysis for goodness-of-fit to expected genetic ratios.

Seedlings that had been selected as resistant in the greenhouse screening were planted in the vineyard in Mar. 1994. They were spaced $1 \mathrm{~m}$ apart in four rows $30 \mathrm{~m}$ long. For the single season evaluation, the grapevines were allowed to grow two main canes that were tied to a stake. No fungicides were applied to these four rows. The seedlings were evaluated for anthracnose symptoms in August, and plants with $<10$ total foliar lesions were considered to be resistant.

\section{Results and Discussion}

Effect of inoculum concentration. In preliminary tests, concentrations of $10^{3}$ and $10^{4}$ conidia/mL resulted in very few symptoms on seedlings from selfed 'Blue Lake' or 'Lake Emerald' grapevine (data not shown). The optimum inoculum concentration for identifying the resistant segregants of selfed 'Blue Lake' and 'Lake Emerald' was $\approx 10^{6}$ conidia/ $\mathrm{mL}$ (Fig. 1a). Inoculum concentrations of $10^{5}$ and $5 \times 10^{5}$ conidia/mL failed to induce sufficient disease symptoms on all of the susceptible seedlings. Concentrations of $5 \times 10^{6}$ or $10^{7}$ conidia/mL were satisfactory, but did produce symptoms in some seedlings that should have been resistant to anthracnose, based on the known R:S genetic ratio obtained from field studies (Mortensen, 1981).

Incubation temperature. Resistant seedlings were most accurately and consistently separated from susceptible seedlings following 24,48 , and $72 \mathrm{~h}$ incubation in the moist chamber at temperatures of 20,24 , and $28^{\circ} \mathrm{C}$ (data not shown). With temperatures $<20^{\circ} \mathrm{C}$
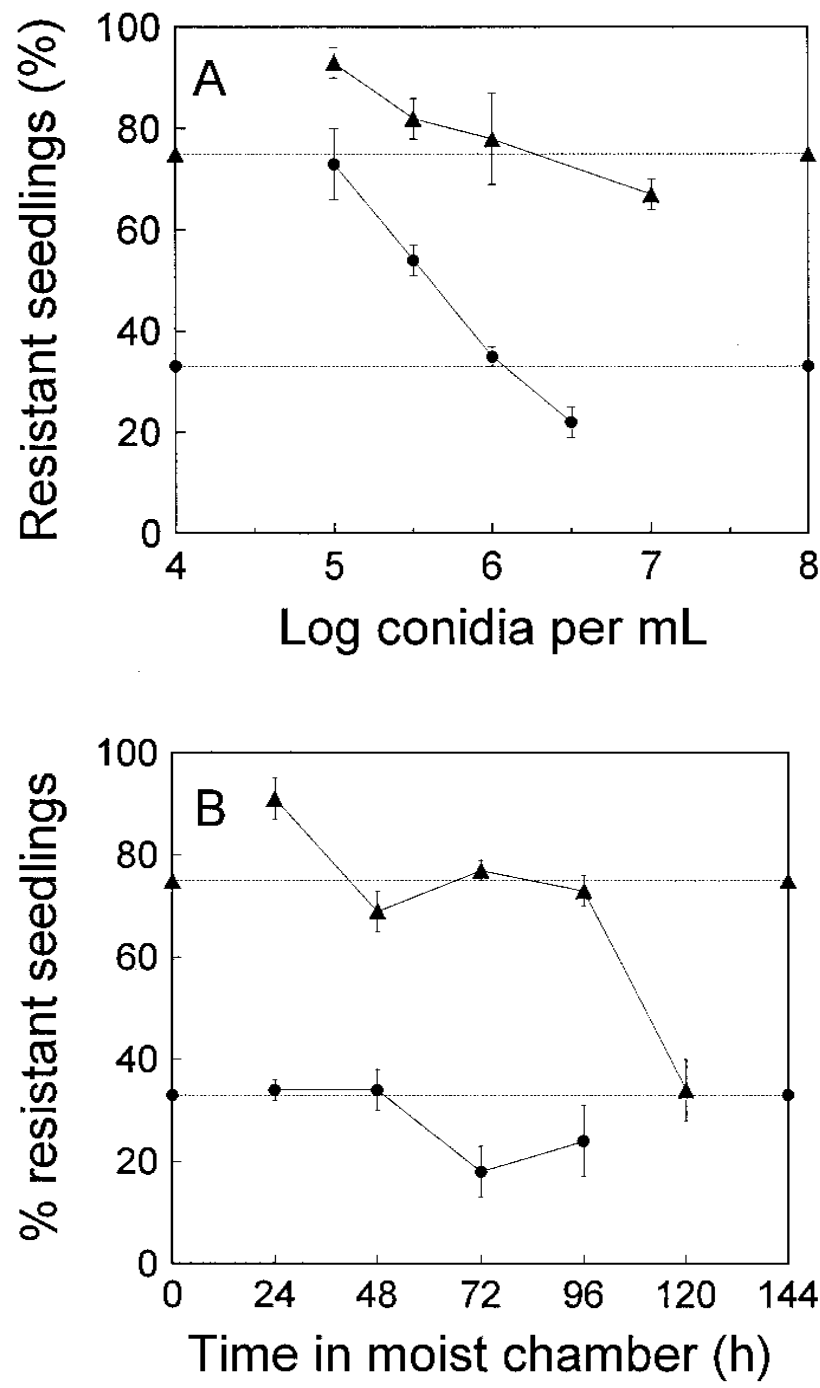

Fig. 1. Effects of (A) inoculum concentration and (B) length of time in a moist chamber with a median temperature of $24^{\circ} \mathrm{C}$ on the percentage of anthracnose-resistant seedlings from selfed 'Blue Lake' $(\boldsymbol{A})$ and 'Lake Emerald' (O) grapevines observed in greenhouse inoculations. Dotted lines represent the expected percentage of resistant seedlings in 'Blue Lake' and 'Lake Emerald' based on the known R:S genetic ratios (Mortensen, 1981). Vertical bars represent standard error above and below the mean.

Table 1. Comparison of observed and expected ratios of anthracnose resistant to susceptible seedlings of progeny from three commercial grape cultivars evaluated with the greenhouse screening procedure.

\begin{tabular}{lcccccc}
\hline & \multicolumn{2}{c}{ Progeny observed } & & \multicolumn{3}{c}{ Expected ratios } \\
\cline { 2 - 3 } \cline { 5 - 7 } Source of seedlings & Resistant & Susceptible & & $(\mathrm{R}: \mathrm{S})^{\mathrm{y}}$ & $\chi^{2}$ & $P$ \\
\hline Blue Lake, selfed & 50 & 22 & & $3: 1$ & 1.19 & $0.50-0.25$ \\
Lake Emerald, selfed & 17 & 28 & & $21: 43$ & 0.51 & $0.50-0.25$ \\
Stover, selfed & 19 & 49 & & $21: 43$ & 0.73 & $0.50-0.25$ \\
Stover x Blue Lake & 22 & 19 & & $1: 1$ & 0.22 & $0.75-0.50$
\end{tabular}

${ }^{\mathrm{z}}$ Seedlings of cultivars with known genotypes for resistance to anthracnose were obtained by self-pollinating or crossing cultivars whose genotypes were described previously (Mortensen, 1981).

${ }^{\mathrm{y}} \mathrm{R}=$ resistant, $\mathrm{S}=$ susceptible.

or $>28^{\circ} \mathrm{C}$, longer periods of time in the chamber were required to produce symptoms in susceptible seedlings and the results were more erratic (data not shown). These results are consistent with previously reported optimal temperatures for disease development (Mirica, 1988); therefore, $24^{\circ} \mathrm{C}$ was chosen as the temperature for further experiments.

Duration of moist chamber incubation. At a median temperature of $24^{\circ} \mathrm{C}$, 'Blue Lake' segregants were successfully separated into the expected ratio of resistant to susceptible seedlings (Mortensen, 1981) with a 48- to 72$\mathrm{h}$ incubation period in the moist chamber, whereas with 'Lake Emerald', a 24- to 48-h period was best (Fig. 1b). Based on these experiments, $48 \mathrm{~h}$ was selected as the duration of incubation. 
Validation of greenhouse screening method. Based on the results described above, a screening procedure to select anthracnoseresistant seedlings was formulated. Seedlings in the two-to-three true-leaf stage were inoculated by misting with a $10^{6}$ conidia/mL spore suspension prepared from a 3- to 4-week culture of E. ampelina on potato dextrose agar. After inoculation, the seedlings were placed in a moist chamber for $48 \mathrm{~h}$ at $24^{\circ} \mathrm{C}$. Upon their removal, seedlings were placed on a greenhouse bench and anthracnose symptoms were evaluated $10 \mathrm{~d}$ after inoculation. Seedlings with $<10$ small foliar lesions were considered resistant.

In a test evaluating this screening procedure, progeny from three commercial grape cultivars that were selfed had the expected ratio of resistant-to-susceptible seedlings (Mortensen, 1981), as did the progeny from a cross between two of the cultivars (Table 1) All tests were within normal variation and support the validity of the screening proce- dure. While the resistant-to-susceptible ratios were similar to those expected from previous field studies and genetic analysis (Mortensen, 1981), we wished to confirm that these selected resistant seedlings also were field-resistant. Less than $5 \%$ of the plants judged resistant in the greenhouse were found susceptible to anthracnose under vineyard conditions (data not shown). Thus, most seedlings resistant to anthracnose in this greenhouse screening procedure also were resistant to natural infection in the vineyard. The four to five seedlings that were resistant by the greenhouse screening procedure and developed symptoms in the field could have been escapes in the greenhouse inoculation. In a grape breeding program, these few susceptible seedlings would be eliminated quickly and with minimal cost in field testing. The greenhouse procedure to select grapevine cultivars and breeding lines resistant to anthracnose is an accurate, economical, and laborsaving method.

\section{Literature Cited}

Brook, P.J. 1973. Epidemiology of grapevine anthracnose, caused by Elsinoe ampelina. J. Agr. Res. 16:333-342.

Fennell, J.L. 1948. Inheritance studies with the tropical grape. J. Hered. 39:54-64.

Halbrooks, M.C. and J.A. Mortensen. 1989. Origin and significance of Florida hybrid bunch grapes and rootstocks. HortScience 24:546-550.

Hopkins, D.L. 1973. Fungicidal control of bunch grape diseases in Florida. Proc. Florida State Hort. Soc. 86:329-333.

Mirica, I.I. 1988. Anthracnose, p. 18-19. In: R.C. Pearson and A.C. Goheen (eds.). Compendium of grape diseases. APS Press, St. Paul, Minn.

Mortensen, J.A. 1981. Sources and inheritance of resistance to anthracnose in Vitis. J. Hered. 72:423-426.

Rogers, D.J. and J.A. Mortensen. 1979. The native grape species of Florida. Proc. Florida State Hort. Soc. 92:286-289.

Tanaka, S., K. Katumoto, and Y. Yukawa. 1974. Studies on the grape anthracnose, Elsinoe ampelina I. Cultural aspects of the fungus. Bul. Faculty Agr. Yamaguti Univ. 25:917-946. (abstr. Rev. Plant Pathol. 54:856. 1975). 